\title{
Emotion theory in education research practice: an interdisciplinary critical literature review
}

\author{
Joy A. R. Eliot ${ }^{1} \cdot$ Atsusi Hirumi $^{2}$ \\ Published online: 6 February 2019 \\ (C) The Author(s) 2019
}

\begin{abstract}
In this critical literature review, we seek to understand why multidimensional, psychological measures of human emotion that have been popular in the study of emotion and learning to date, may not yield the statistical power or construct validity necessary to consistently explain or predict human learning. We compare competing theories and conclude that educational studies tend towards use of multi-dimensional models of human emotions which, while useful in educational psychology and therapeutic practice, suffer from psychometric flaws and generate lower power when used as empirical research constructs compared with the "basic emotion" models and their derivatives popular in the neurobiological, cognitive, and social sciences. Based on our review, we conclude that more extensive use of physiological measures and analysis of spontaneous emotion language, both rooted in the basic emotions tradition rather than continued psychological measurement of multi-dimensional emotions, may yield more consistent and significant results and reduce education researchers' reliance on self-report measures. Findings from the review may advance the selection of operational definitions and formulation of research questions for new empirical studies of the intersections between emotion and learning.
\end{abstract}

Keywords Emotion $\cdot$ Measurement $\cdot$ Neuropsychology $\cdot$ Affective domain

Despite the clear relevance of emotions for education and the dramatic increase of attention to emotion in other scientific disciplines, such as neuroscience, economics and the humanities, educational psychology has neglected emotions. (Pekrun and Stephens 2012, p. 3).

The charge, raised in an authoritative handbook, that educational psychology had still "neglected emotions" as late as 2012, invites pressing inquiry. Despite innovations in the study of human emotions and cognition beginning with Damasio's Descartes' Error

Atsusi Hirumi

atsusi.hirumi@ucf.edu

1 College of Community Innovation and Education, University of Central Florida, 4221 Andromeda Loop, Orlando, FL 32816, USA

2 College of Community Innovation and Education, University of Central Florida, Orlando, FL 32826, USA 
in 1994, the publication of LeDoux's The Emotional Brain in 1996, and the rush of proposed changes in curriculum and professional development that followed the popularization of emotional intelligence (EI/EQ), Pekrun and Stephens described the state of empirical research on the relationship between emotion and learning as "neglected" in the recent past.

The purposes of this critical review are to synthesize the main taxonomies of human emotions in use across the social sciences and weigh their differential value in empirical research on emotion and learning. Both psychometric and empirical evidence suggests that the dominance in education literature-particularly in the domain of technology and education-of academic emotion theory, a taxonomy whose purpose was originally therapeutic rather than predictive, is associated with weaker statistical relationships between emotions and learning outcomes than other terms associated with basic emotions the intensity/ valence schemas derived from and incorporating the premises of basic emotion theory. It may therefore be hypothesized that, as scholarship on learner emotions expands, reduction in use of the academic emotions in favor of constructs preferred in other social sciences may increase the power and replicability of new findings in technology and learning.

The present study originated as a literature review in response to Pekrun and Stephens' (2012) warning about the neglect of emotion in education research-initially, a review of the relation between physiological measures of human emotion and learning through technology. Relatively little extant material emerged, even outside the educational technology subfield. As a result, the purpose of the study shifted towards a critique of operational definitions not the synthesis originally expected. A critique of definitions is merited since, if education research persists in using constructs that are out of line with those current in other disciplines, it becomes difficult either to apply interdisciplinary theory or to design generalizable treatments or measures (Bostwick et al. 2014). In this paper, the dominant taxonomies of emotion are organized into three main groups-basic, multidimensional, and academic. The authors then express concerns about the use of the academic emotions in empirical research and compare the state of the affective sciences in the social sciences generally to that in educational technology research specifically.

\section{Method}

Because the study of emotion crosses disciplinary boundaries between education, cognitive psychology, neuropsychology, evolutionary psychology, and philosophy, more wide-ranging search methods than the standard procedure of searches through high-rated journals within a discipline were necessary. The authors used a mixture of Boolean search strings through OneSearch (e.g., contempt AND neuroscience, anger AND neuroscience, anger AND learning), and Science Direct's pearl-building techniques in article bibliographies to identify seminal works. Search terms became more sophisticated as the project grew clearer. The bibliography of the Stanford Encyclopedia of Philosophy's entry "Emotion" (de Sousa 2013) also grounded the search, as the majority of recent seminal works on emotion from a philosophical viewpoint are in book format and therefore would not appear in a search through journal databases.

Only peer-reviewed works are included in the review. In addition, the pattern of research followed qualitative traditions of emergent methodology, which changed based on early findings. The initial plan called for the inclusion of works solely related to the interconnections between emotion and learning through technology, but D'Mello's (2013) 
meta-analysis on affective states and learning suggested that not enough persuasive research has been completed for our original research question to remain informative. Thus, focus shifted from reviewing strictly physiological treatments of emotion and learning toward determining why, based on search results, psychological measures of human emotions may not yield the power necessary to consistently explain or predict human learning. The proposed approach to categorizing major subsets of emotion theory, despite the diversity of concepts involved in this endeavor, has much in common with Bostwick et al.'s (2014) "ontological" process for critical theory as well as Steiner (1988) on methods for theorybuilding. The authors share Bostwick et al.'s concern about philosophically naïve bricolage from a variety of multidisciplinary sources "with little or no regard for their corresponding theoretical or philosophical assumptions and implications" (p. 572). Trans-disciplinary work takes on greater methodological rigor when the theoretical underpinnings of operational terms are the main unit of analysis. This approach avoids the equally serious risks of creating false analogies based on natural language interpretation of terms that authors may use in contestable senses, and of overlooking philosophical similarities between schemes obscured by use of different parts of the immense vocabulary of emotion-a downfall of keyword searches, for example.

\section{Limitations}

The fundamental mismatch between the terms used in education scholarship (which tend to be derived from Pekrun's 2011 Achievement Emotions Questionnaire) as opposed to other fields (where terminology most often follows the basic emotion schemes proposed by Ekman et al. (1969), Panksepp (1994), and similar scholars) has made meta-analysis in the mathematical sense impractical, since it is difficult to know whether like is being compared to like when terms do not align. While the following conclusions may potentially spur experimental research, this paper represents a qualitative critique of existing research and theory as a method of refining our understanding of theoretical concepts and definitions, rather than developing yet another novel conceptual scheme.

Study parameters exclude issues connected with emotional intelligence theory, except in terms of the comparative intellectual history of Pekrun and Stephens (2012) versus competing models. The core of emotional intelligence theory is emotional regulation, often accompanied by the idea that no intense emotion is conducive to success in learning or other endeavors (Mayer and Geher 1996; Goleman 1995; Bar-On 2006). The authors seek to review the relationship between emotional states and learning, rather than emotional regulation; therefore emotional intelligence is not germane to this paper. Likewise, not all seminal works treating the topic of emotion and cognition are included, but only those that focus on defining the terminology and taxonomy of discrete emotions. Thus, for example, works of evolutionary psychology such as Greenspan and Shank (2009), Greenspan and Benderley (1997), and Kandel (2001) have not been included in the review; the literature proposing causal links between emotion and the development of intelligence is provocative, but not germane to a discussion of which emotion terms best to use in research into education and technology. Furthermore, while in time a theory of unified affecto-cognition which dispenses with the traditional dichotomy of reason and emotion may be valuable for research, such theory to date lacks instruments that are ready for use in empirical study. The authors therefore maintain an agnostic view of whether emotion is a discrete mental 
phenomenon or rather a subspecies of cognition, as defined for example in Nussbaum (2001) and Ben-Ze'ev (2000).

Studies about fear, stress, and test anxiety are beyond the scope of this review, and thus excluded. It is well established in the literature that chronic or toxic anxiety, as opposed to eustress or beneficial stress, is correlated with poor learning outcomes (see Zeidner 1998; Eysenck 1997; Seipp 1991; Selye 1976; Sharpe n.d.). Those interested in learning more about stress, human learning and performance are encouraged to read Zeidner, Eysenck and Selye.

Finally, a limitation of the literature that creates a corresponding limitation of this review is the lack of a major longitudinal study related to emotion and learning. Were this to be conducted, the results would constitute a contribution to knowledge that would repay the difficulty and expense of this methodology.

The authors have mainly followed Cooper's (1985) method for literature reviews, but dissent on one point: her tenet that excessive questioning of definitions should be avoided. In this case, the definitions proved to be one of the most fertile areas for metatheory. Scholars without a common understanding of key terms may talk past each other-which appears to be one root cause of the problem. The review thus begins with an examination of three common approaches to explaining and predicting human emotions. The authors then note experimental, psychographic, and conceptual concerns with academic emotion theory and critically review the state of both neuropsychological and educational research on human emotions.

\section{Three approaches to studying emotions}

The review of literature revealed three basic approaches to the study of human emotions and learning. These are here classified as basic emotion, multidimensional emotion, and academic emotion theory.

\section{Approach 1: basic emotion theory}

While the exact number and identity of the basic emotions varies between theorists, basic emotion theory emerged from Darwin's understanding of the function of facial expression as formulated in The Expression of the Emotions in Man and Animals (1872). The concept of basic emotions received an important experimental boost, relevant to a global education market, when Ekman et al. (1969) found that observers in the United States, Japan, New Guinea, Brazil, and Borneo were able to accurately identify facial photographs representing happiness, surprise, fear, disgust/contempt, anger, and sadness (cf. Jack 2013).

Recent developments suggest notable differences between Western and Asian facial expressions (Jack 2013). Yet, the physical expression of basic emotions (e.g., flaring of the nostrils for anger vs. tightening the nostrils in disgust) does suggest some commonality rooted in human biology, modulated in subtle ways by language and culture (Jack 2013). While competing schemes include between five and ten basic emotions, the descriptive words, such as fear, disgust, anger, and happiness, are relatively simple and familiar. 


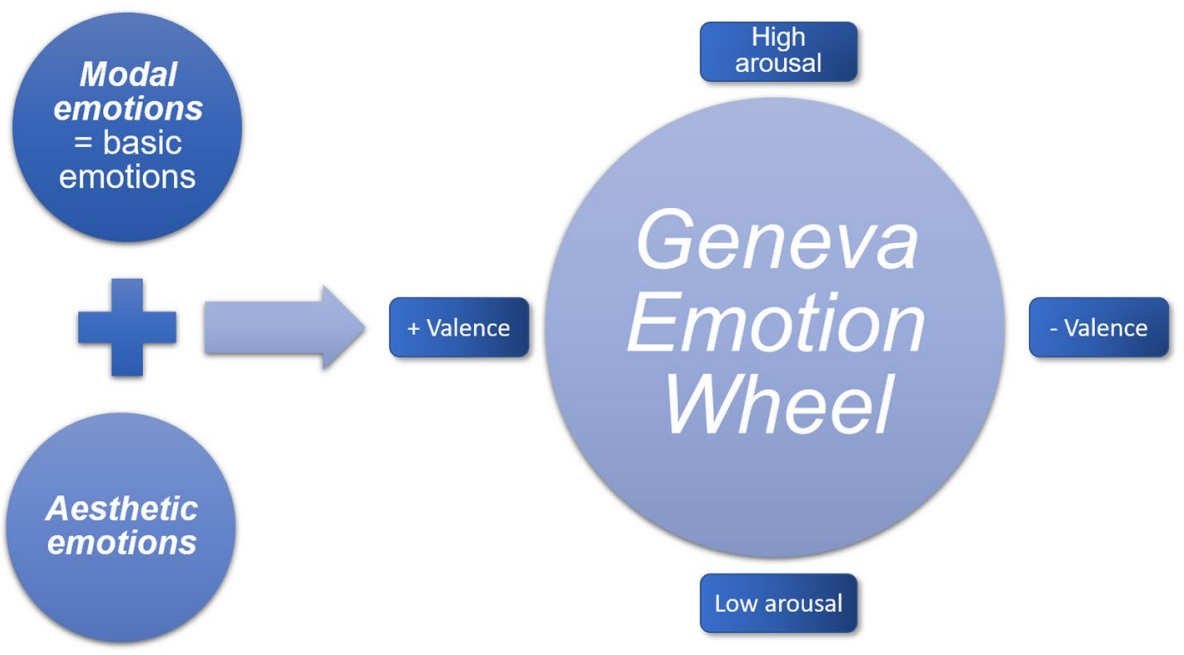

Fig. 1 Theoretical derivation of the GEW

More complex emotions are viewed at times as a simultaneous experience of more than one basic emotion an approach that might be termed semantic emotion (sentence-like structures composed of multiple emotions conjoined). However, basic emotion theory remains distinct in its reliance on a small number of discrete, discontinuous states described by words that are as culturally unmarked, related to facial expressions with plausible evolutionary functions.

\section{Approach 2: multidimensional emotion theory}

Basic emotions have been developed into more complex models intended primarily for psychotherapeutic purposes, such as Plutchik's emotions cone (Plutchik 2000, p. 63, Fig. 4.1). Such models depend on a small number of primary emotions onto which the wide variety of emotions encountered in psychotherapeutic practice can be mapped.

The Geneva Emotional Wheel (GEW) (Scherer 1994, 2005), is a similar multidimensional model that developed from basic emotion theory-Scherer retains the concept of basic emotions wholesale except for renaming them modal emotions — with a goal of allowing qualitative researchers, as opposed to therapists, to use natural-language data from their participants in an organized way. Scherer graphs emotions on a two-axis model, with one axis representing positive versus negative valence and the other low versus high arousal, synthesizing the wide variety of emotions found in natural language into a universal model. Scherer's underlying construct includes the validity of the basic emotions, but uniquely includes an additional range of non-Darwinian aesthetic emotions, theorized to be unique to humans and to lack evolutionary survival value, derived from Kant (2000) aesthetic philosophy-for example, awe (Fig. 1).

A frequently overlooked element of the GEW, which Scherer acknowledges (pp. 722-724) but graphic presentations of the GEW tend to obscure for the sake of graphic design, is that it shares the asymmetry between the positive and negative valences seen in standard basic emotion theory. While the GEW is generally rendered as a perfect circle, there are considerably more attested words on it that describe negative or unpleasant 


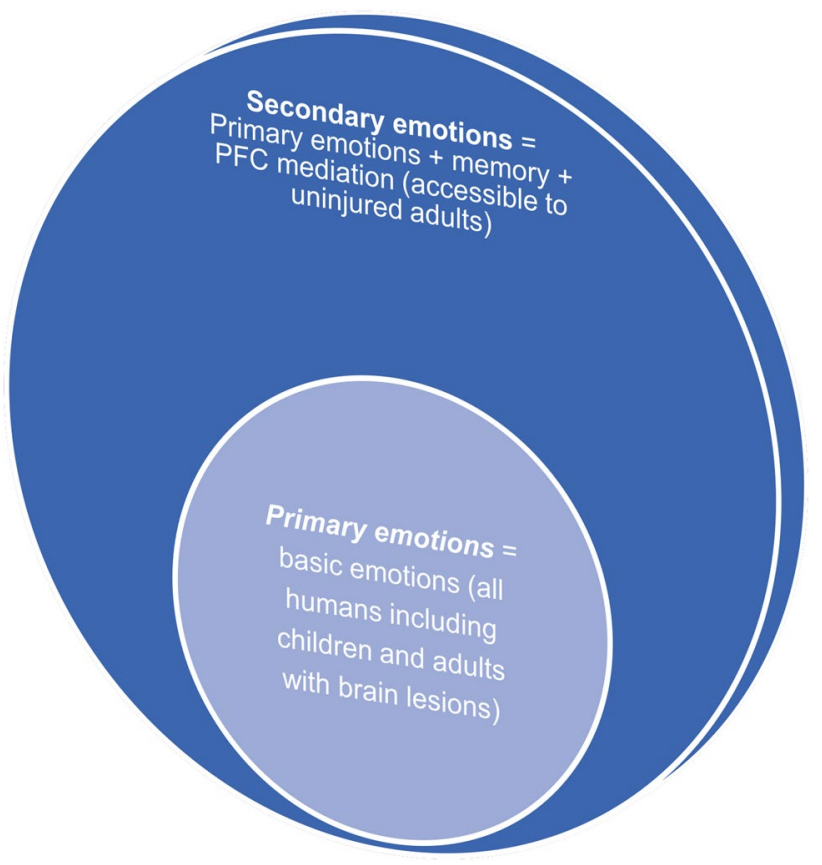

Fig. 2 Relationship of primary to secondary emotions according to Damasio

emotions than positive ones. Full consideration of the GEW exceeds the scope of this paper. However, the GEW's methodology and intended use in research situate it nearer to a particularly complex development of basic emotion theory than to academic emotion theory or an independent theoretical tradition, and it is usable by researchers who reject its Kantian elements if they merely define words that Scherer classifies as expressions of aesthetic emotion as outside the boundaries of their studies.

Damasio (1994), like Scherer (1994, 2005), proposed a two-dimensional emotion taxonomy of primary and secondary emotions, the influence of which on education is seen particularly in the work of Greenspan and contributors (e.g., Greenspan and Benderly 1997). Unlike Scherer, Damasio (1994, pp. 134-138), does not demarcate primary and secondary emotions at the boundary between the emotions of humans versus those of other animals, but rather the boundary between the emotions of normative adult humans versus those of either human children or humans with lesions in the brain. Any human, according to Damasio's theory, can experience basic emotions, which he explains as activations of the autonomic nervous system (ANS) in response to stimuli, including both brain and peripheral neuron reactions-a distinctive of Damasio's theory. In short, he considers the peripheral nervous system to be a part of the thinking apparatus, and that restricting cognitive neuroscience to the study of the brain may be a philosophical and methodological error.

However, in an adult with a fully developed prefrontal cortex (PFC) (which does not mature until late adolescence in most humans), Damasio permits an additional, less immediate emotion mechanism modeled as a complex interaction between basic ANS reactions, recall of memories related to the immediate stimulus, and the mediating action of the PFC to create a potentially complex and nuanced emotional reaction 


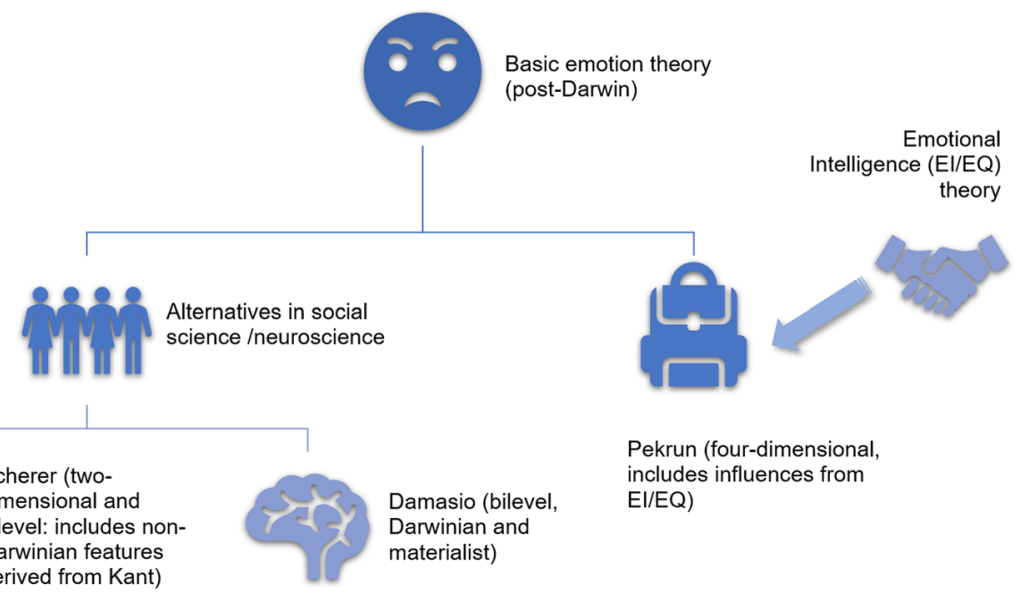

Fig. 3 Intellectual history of emotion taxonomy types

(Fig. 2). Using this model, Damasio accommodates experiences such as ecstasy and awe that would otherwise fall under Scherer's aesthetic emotions, as well as accounting for the social emotions, such as guilt/remorse and schadenfreude (Damasio 1994, pp. 149-150). As evidence for the scientific validity of this two-tiered system, Damasio cites clinical evidence that patients with PFC lesions can experience basic emotions in response to immediate stimuli, but cannot experience the secondary emotions (1994, pp. 138-139).

In summary, the multidimensional approach can be imagined as moving beyond semantic combinations of more than one emotion into a conception rooted in geometric dimensions. If semantic developments of basic emotion theory are like simple sentences or word equations, multidimensional theories are both imaged and conceived like geometric figures or solids, with at minimum an $\mathrm{X}$ and $\mathrm{Y}$ axis.

\section{Approach 3: academic emotion theory}

Although it is also multidimensional in nature, having four axes, we distinguish academic emotion as a separate approach because of its separate origin and focus on learning and practice within schools, including school counseling offices. In contrast to other multidimensional theories, academic emotion is largely the work of Pekrun and his various contributors, as shown below by their bibliography, as opposed to originating from an interdisciplinary tradition. Every paper reviewed that uses academic emotions as a defining research construct cites Pekrun, and the vast majority of studies focus on the relation between emotion and learning. By contrast, Pekrun is rarely if ever cited outside education studies. Academic emotion theory can thus be distinguished from general multidimensional emotion theory partially because of its separate intellectual history (Fig. 3). However, convergent evolution has not occurred along these parallel lines of theory building. 
Pekrun defines a complex, markedly symmetrical taxonomy of emotions, including achievement emotions, epistemic emotions (including curiosity, confusion and frustration), and social emotions. The academic emotions are arranged around three axes: positive/negative, activity focused/outcome focused, and activating/deactivating, in addition to the three categories of achievement, epistemic or emotional. One can presume that, while conceptually this is a four-dimensional scheme, Pekrun et al. (2011, p. 37) refer to it as three-dimensional, not calling the achievement/epistemic/emotional categories a dimension most likely because they would then be faced with the task of drawing a four-dimensional diagram. While Pekrun et al. (2011) have preferred the term control-value theory for this schema, the simpler label academic emotion theory more clearly reflects its afterlife in empirical studies of learning that use emotion as a variable and adopt Pekrun's AEQ instrument, but not necessarily his theory and philosophy of emotion. ${ }^{1}$

The development of academic emotion theory has been paralleled by the ongoing validation of an instrument, the Achievement Emotions Questionnaire (AEQ), which has generated variants for use in different age groups, subject areas, and languages in addition to the original English. The psychometric history of the questionnaire is mildly checkered. The Pekrun et al. (2011) validation study, the earliest such study conducted of the AEQ, with a convenience sample of $N=389$ undergraduate psychology students volunteering for extra credit, relied predominantly on structural equation modeling to demonstrate the alignment of the questionnaire with the theoretical model and correlation analyses to show that positive academic emotions correlated with one another across different domains of academic life, as did negative emotions.

Analysis of constructs by Cronbach's $\alpha$ was performed, but the results are sparsely discussed by the authors, as six of the 24 constructs measured do not achieve the generally accepted cutoff value of $\alpha=0.80$. A study by Lichtenfeld et al. (2012) on which Pekrun was the second author did not mention Cronbach's $\alpha$ at all, making its argument purely on the basis of structural equation modeling (SEM) and Pearson product-moment correlations. These procedures tell the reader only that the theory and the questionnaire are consistent with one another; the omission of Cronbach's $\alpha$ implies that there is no discussion of whether any of the constructs are either internally confused or redundant.

Two 2017 psychometric studies of the AEQ suggest that its validity is in fact questionable. Starkey-Perret et al. (2017), working with a sample of $N=299$ consisting of all pupils at an urban French middle school (thus eliminating the convenience sampling and self-selection of participants likely to be high in positive emotions generated by academic work created by an extra credit participant selection strategy), found that 15 of the 18 constructs in the version of the AEQ used fell below Cronbach's $\alpha=0.80$, with the lowest scores clustering around emotions such as pride and shame that basic emotion scholarship would frequently consider social rather than primary emotions, or mental states that should not be classed as emotions at all. The study by Hong et al. (2017) of $N=358$ East Asian K-12 teachers taking a variant of the AEQ designed for teachers not only had no values of Cronbach's $\alpha$ higher than 0.80 on any of its four constructs except for anxiety-and only when measured separately for only the Japanese and not the Korean participants-but also demonstrated considerable cross-contamination between anger and frustration (p. 98). No basic emotion theorist disambiguates anger from frustration as a matter of quality rather than intensity or socially preferable word choice; doing so is one of distinctive features of

\footnotetext{
1 The authors question Pekrun's reading of de Sousa (1987); however, that is a philosophical inquiry that exceeds the central aim of this paper, which is to further future empirical research.
} 


\begin{tabular}{|c|c|c|}
\hline Basic Emotion & $\begin{array}{c}\text { Multidimensional } \\
\text { Emotion }\end{array}$ & Academic Emotion \\
\hline $\begin{array}{l}\text { - Best-known } \\
\text { theorist: Ekman } \\
\text { - Small number of } \\
\text { emotions } \\
\text { identified with } \\
\text { natural language } \\
\text { words. } \\
\text { - Intended use: } \\
\text { experimental } \\
\text { research }\end{array}$ & $\begin{array}{l}\text { - Best-known } \\
\text { theorist: Scherer } \\
\text { - Emotions } \\
\text { arranged on two } \\
\text { axes, often of } \\
\text { intensity/valence } \\
\text { - Intended use: } \\
\text { primarily } \\
\text { qualitative } \\
\text { research }\end{array}$ & $\begin{array}{l}\text { - Best-known } \\
\text { theorist: Pekrun } \\
\text { - Emotion words } \\
\text { taken from } \\
\text { natural language } \\
\text { and arranged on } \\
\text { four axes. Very } \\
\text { high number of } \\
\text { discrete terms. } \\
\text { - Intended use: } \\
\text { therapy }\end{array}$ \\
\hline
\end{tabular}

Fig. 4 Taxonomy of emotion taxonomies

Pekrun's schema that is not shared with scientists working in the non-academic traditions of emotion study.

Based on the bibliography of Pekrun and Stephens (2012), academic emotion theory has been developed in parallel to rather than in concert with basic emotion theory. Of Pekrun and Stephens's 153 total citations, $49.6 \%$ come from specifically educational studies or journals, and they cite few seminal works outside education and psychology.

Another major methodological difference between Pekrun and Stephens (2012) and theorists from the schools represented by Ekman, Panksepp, Scherer, or Damasio is Pekrun and Stephens' heavy reliance on emotional intelligence theory (ten citations explicitly referencing emotional intelligence, though one is partially critical), a method not seen elsewhere. This distinction is reflected in the simplified diagram of the intellectual history of major post-Darwinian schools (Fig. 3). A full assessment of emotional intelligence theory lies beyond the scope of this project; however, it is notable that the recent critiques of the concept of emotional intelligence in fields such as personality science have not penetrated education research, though to their credit Pekrun and Stephens use the fully scientific version of the construct proposed by Mayer et al. (1999) and Bar-On (2006) more extensively than the controversial and quasi-scientific version by Goleman (1995).

The multiple axes and domains posited by academic emotion theory allow for a finegrained classification of the large vocabulary of emotion words relating to schoolwork that may be heard by a practicing school counselor or educational psychologist. A counselor aims to understand a learner's natural language, not to spend time splitting hairs to fit the learner's self-expression into a scientifically verifiable taxonomy. Nevertheless, while the appeal of academic emotions for a school psychologist or a clinical therapist is transparent, when constructs recognized as emotions only by multidimensional schemas are applied to research questions, the result tends to be markedly lower or insignificant $p$-values compared to the basic emotions used in the same study (Fig. 4). 


\section{Concerns for multidimensional approaches}

The authors posit that, despite the sophistication of such models of emotions, in practice, multidimensional theories of emotion may limit $p$-values and effect sizes if their concepts are used in empirical studies of the relationships between emotions and learning, particularly learning with technology. In addition, scholars should consider that complex, multivariate theories of emotions such as Pekrun's are intended for "psychological and educational" purposes more than research (Pekrun and Stephens 2012, p. 4); if so, it is likely that the ambiguous results found in the empirical research stem from using a tool for a purpose for which it was never designed.

While it is the case that a limited subset of concepts distinctive to the Achievement Emotions Questionnaire (AEQ) have been shown to be reliable on questionnaires by both Cronbach's $\alpha$ and factor analysis (Pishghadam et al. 2016), reliability does not guarantee validity; in addition, Pishghadam et al.'s questionnaire derived from the AEQ includes far fewer distinct constructs than the questionnaires discussed above that demonstrated low values of Cronbach's $\alpha$ for most of the concepts distinct to academic emotion theory. That AEQ concepts are sometimes statistically reliable in survey research shows that respondents perceive the words as referring to distinct constructs, but it does not prove that those constructs are biologically as opposed to linguistically distinct, nor that all of them are best described as emotions rather than other mental states-Pishghadam et al. (2016) achieve the strongest validity measures for boredom, an experience which no reasonable person would say did not exist, but which, as discussed in more detail below, is questionably identified as an emotion.

Expansive vocabulary is valuable to a practicing counselor, but this expansiveness may, when transferred to the domain of neuropsychological research, have unintended consequences. The fine distinctions of natural language may not correspond to distinguishable brain structures or processes.

\section{Experimental concerns}

First, many emotions found in multidimensional theories may be explicable as complex constructs of basic emotions combined with each other and/or with propositional beliefs that are not necessarily emotional: e.g. anger [at the difficulty or perceived unfairness of a task] + fear [of the consequences of not doing it]+ metacognitive awareness that "I don't get it"=confusion; flow [induced by the learning stimulus]+metacognitive awareness that "lines up with previous knowledge/interests of mine" = curiosity, etc. Such a syntactic presentation of the academic emotions, as combinations of multiple basic emotions with propositional beliefs, retains the intuitive appeal of systems that permit larger natural-language vocabularies, but may avoid the risks to significance and power that accrue from reifying the academic emotions. It would possess some continuity, though not identity, with the philosophical model of emotion as a continuum between schema-creating mental events and more straightforwardly cognitive events proposed by de Sousa (1987) and Rorty (1980). The experimental work of Harley et al. (2012) achieves promising results with a similar approach, as discussed below.

The fine-grained taxonomy and large vocabulary of the AEQ has a strong appeal to lived experience, and its elegant symmetry may also appeal on a subconscious aesthetic level. However, most of its constructs are extremely hard to measure. For instance, the number of potential emotional states in academic emotion theory require studies to rely on self-report 
(Pekrun and Stephens 2012), most frequently using the AEQ or one of its derivative instruments. Although self-report data can never be completely abandoned in emotion research, since words must eventually be related to brain states before the brain states can be discussed (Nussbaum 2001, p. 9), these measures are flawed if used alone, since they operate on the questionable assumption that participants have excellent self-knowledge about their own emotions. The validity of the AEQ as a sole instrument is open to question, especially in the case of the adolescent subjects who are frequently central to education research. Issues become apparent if using an Erikson-influenced model of adolescence (Finkenauer et al. 2002), given the inherent fluidity of self-concept during this developmental stage.

Self-report of emotion is subject to contamination by "participant answering style, social desirability, interpretation of questionnaire item wording, or limits of participant memory" (Kivikangas et al. 2011, p. 183). In addition, self-deception of one's emotions seems to be a valid concern on both philosophical (Damm 2011) and clinical levels (e.g. Leong et al. (2013) on the efficacy of repetitive transcranial magnetic stimulation on the mindfulness of major depressive disorder and bipolar patients, which implies that under normal circumstances such subjects are impaired in "perspective on the self"). Self-deception may also be magnified if a sample includes subjects with undiagnosed mood disorders, which is likely in large- $N$ research. These concerns are equally valid with adult learner populations as with children or adolescents.

Self-report data is also limited temporally. If an AEQ or similar questionnaire is administered as a posttest, then technically the researcher is not gathering data about learners' emotions during instruction, but about their memories of those emotions, which may already be distorted by nostalgia or other forms of false memory. Real-time data would be of greater value in assessing patterns of emotional and cognitive change in the course of learning.

Likewise, the generalizability of academic emotions research has thus far been limited. In his 2014 meta-analysis of 24 studies on affective states during learning with technology, D'Mello (2013) discovered negative correlations with adequate $p$-values between learning outcomes and negative basic emotions (contempt, anger, disgust, sadness, anxiety) and a positive correlation with flow (the centrality of flow state to happiness is amply demonstrated in Csikszentmihalyi's corpus (1990) and the later tradition of positive psychology and distinguishable as a discrete neural event in Ulrich et al. (2014)). D'Mello (2013) finds insignificant and puzzling data for emotions much more frequently in studies of academic rather than basic emotions (p. 1090, Table 3). D'Mello also notes that students were likely to under-report positive experiences, most often defined by researchers as engagement or flow and over-report boredom and frustration; while he sees here potential for a more complex meta-analytic model, questioning the validity of academic emotion terms may be a more productive research rationale than elaborate statistical analysis on studies with a median $N=39$ (p. 1086).

\section{Theoretical concerns}

In addition to experimental limitations, we believe that multidimensional theories of emotion may suffer from fundamental flaws in construct that may contribute to inconsistent experimental results. Some of the supposed emotions found only in the academic emotions scheme are arguably mischaracterized as emotions rather than other types of mental events. To expand this point, interdisciplinary content may be of value to educators. We 
focus on the academic emotions that D'Mello (2013, p. 1090) found most complex and low in power: boredom, confusion, curiosity and frustration.

First, some academic emotions, while meeting criteria for construed mental phenomena, are not well categorized as emotions. A potent strand in the philosophy of mind, originating in antiquity but still current, holds that an emotion, by definition, must have an object (e.g. Nussbaum 2001, pp. 27-30; Ben Ze'ev 2000, pp. 49-50; Ross 1959). Scherer's requirement that an emotion must be "appraisal driven" (2005, pp. 700-701) is similar, with the additional element of salience of the object, "....we do not generally get emotional about things or people we do not care about."

Requiring an object calls into question the status of boredom and confusion in particular. Although ordinary language allows us to say that something bores us (or that we bore someone else), our usage does not line up well with the concept of boredom. Boredom implies disengagement from the object of our thoughts and emotions because of either intrinsic or extrinsic motivating factors. The experimental findings of Weissman et al. (2006) suggest that this subjective perception of disengagement is mirrored by a literal disengagement between brain regions that are connected when the subject is not bored.

Likewise, confusion cannot be understood without an object; confusion implies that the subject is fundamentally disengaged from a learning object. While natural language allows us to say that a student is bored or confused with a subject (e.g. math), by the definitions cited above, it would be more accurate to speak of the student lacking emotion directed at math because math has not reached a sufficient level of salience for the student to experience any emotion, assuming we are talking about boredom or confusion in isolation, and not those experiences co-existing alongside fear of math - the ironic assertion that, within this construct, a student could still be both bored by and afraid of math does not violate the law of noncontradiction, since the student could simultaneously experience low salience for an accurate mental model of math and high salience for a mistaken mental model.

Second, we are concerned that functional magnetic resonance imaging (fMRI) of states recognized as emotions only by Pekrun and co-authors shows them to be far more complex than the basic emotions, and to affect the brain in a qualitatively different way. Consider boredom again: Weissman et al. (2006) found that subjects attempting to complete a tedious task in an fMRI scanner showed lapses in the connections between the processing centers of the brain relevant to the task during those periods when their reactions slowed. Surely there is a profound qualitative difference between an experience that arouses one or more brain areas and one that serves to reduce blood flow in the connections between areas to subnormal levels. Lack of normal arousal and connection matches the concept of boredom as a vacuum of emotion, not one single emotion whose brain signature is the opposite of all others.

Third, some emotions found in academic emotion theory are otiose as concepts, except where required by the pragmatic demands of counseling or therapy. For example, it may be a matter of semantics whether frustration is in fact the same emotion as anger, or is an experience that contains anger alongside beliefs about the task, but is expressed with a milder and more socially sanctioned word (see Plutchik's (2000) discussion of the role of intensity language in nuancing basic emotion theory, p. 61). Reducing the number of emotion words by eliminating synonyms that cannot be distinguished except by context, intensity, or connotation is also promising as an answer to Pekrun and Stephens' (2012) explicit break with the tradition of not differentiating positive emotions to the same degree as negative (p. 9).

The syntactic model is of potential value here for describing supposed emotions, especially curiosity and confusion, which are more plausibly modeled as combinations of 
emotions and relevant propositional beliefs. Including the category deactivating positive emotions (such as relief or relaxation) in the taxonomy has an intuitive appeal for explaining why positive mood does not always appear to correlate with improved performance in the classroom. However, not only do Pekrun and Stephens (2012) describe empirical evidence for behavioral differences between, say, prideful versus relieved learners as "scarce" (p. 9), the search for such evidence is out of step with physiological findings as detailed below. Such findings tend to support the basic emotion concept that positive emotion is less differentiated than negative.

\section{State of emotions research}

Our review indicates that the state of physiological research on human emotions is vibrant, but that educational research on their application lags behind the rest of the scientific disciplines that fall under the emerging descriptor affective sciences. We argue that more robust use of physiological measures will increase the validity and replicability of research into education technology best practice.

\section{Physiological emotions research}

The field of neuropsychology is growing rapidly. An increasing number of studies use instruments such as functional magnetic resonance imaging (fMRI) of the brain, positron emission tomography (PET), electro-encephalography (EEG), galvanic skin reactivity (GSR), and electromyography to associate psychological observations of human behavior and the mind with neurobiological changes in the brain and body. These measures can be divided roughly into two types: those that give highly precise results in terms of brain location, such as fMRI, which measures differential blood flow in the brain, and PET, which detects factors such as blood flow and glucose metabolism through the use of injected radioactive tracers, and those that give near-real-time results, such as electroencephalogram (EEG), which measures electric fluctuations in the brain with electrodes on the scalp, or GSR, which measures arousal by means of detecting otherwise imperceptible amounts of sweat.

In their 2002 meta-analysis of physiological studies on human emotions, Phan et al. reviewed 55 PET and fMRI-based investigations that used Montreal Neurologic Institute brain coordinates to localize happiness, fear, sadness and disgust (Phan et al. 2001, p. 333, Table 1) and found high $p$ value correlations measured by $\mathrm{X}^{2}$ analysis between fear (amygdala) and sadness (subcallosal cingulate cortex). Likewise, in studies of the rare case of an adult woman with brain damage restricted entirely to the amygdala, Damasio and his colleagues found that she could neither recognize fear in pictures of human faces (though she could recognize the other basic emotions) nor be classically conditioned to fear a stimulus (as discussed in LeDoux 1998, p. 173).

In the 12 years since Phan et al., the field has grown rapidly. A cursory review of peerreviewed articles published 2002 reveals a diversity of topics such as the differential processing of fear in the right versus left hemispheres of the amygdala (Dyck et al. 2011), the role of the orbitofrontal cortex in accurately tracking changing emotional valence in others (Goodkind et al. 2012), the role of the frontal cortex in anger, aggression and inhibition (Kelley et al. 2013), neural differentiation of disgust and contempt (Sambataro et al. 2006), 
activation of the amygdala and anterior cingulate (happy) with stimuli lasting only $20 \mathrm{~ms}$ (Killgore and Yurgelun-Todd 2004), fMRI-measured neural correlates of flow (Ulrich et al. 2014), a pilot study of EEG measurement of anger (Jaworska et al. 2012), and a neural analysis of social emotions: guilt, embarrassment, envy, and schadenfreude (Jankowski and Takahashi 2014).

The results of experimental neuropsychological studies depend explicitly on basic emotion theory. Stimulus using standardized facial expressions per Ekman's models is a standard technique used in most experiments, and other than research on social emotions, the results of such investigations depend on the use of limited basic emotion constructs. The Geneva model can potentially be unified with these data as well; Dogan et al. (2014), using a study population of Huntington's disease sufferers to ensure an objective standard of subnormal emotional intensity, found that localization of emotions after stimulus with basic emotion cards was similar to healthy controls, but that amount of blood flow to the same regions was lower. While Dogan did not explicitly use the GEW, his results provide an isolated but valuable example of how the conceptual roots of the GEW, particularly its recognition of the intensity dimension, could be understood and applied outside qualitative studies-though the aesthetic emotions remain difficult for this purpose unless the researcher commits to a philosophically complex body of propositions about the nature of aesthetic experience and indeed human nature.

Research using the more complex constructs typical of academic emotion theory has not progressed similarly - the review of literature revealed no physiological treatments of normal confusion (as opposed to pathological dementia), only one of frustration with findings similar to anger studies (Yu et al. 2014), and one of curiosity (Jepma et al. 2012) which suggested a highly complex neural system qualitatively different from an emotion, much like the findings on boredom by Weissman discussed elsewhere.

Overall, physiological studies of the brain, proceeding from a basic emotions basis, have achieved fine-grained results locating normative positions of the emotions. Like most basic emotion schemes and like Scherer's verbal as opposed to graphic presentation of the Geneva model, neural differentiation of the negative emotions seems to be greater than that of the positive emotions. This is not to imply that brain scans show us to be largely negative beings. However, the relative sameness of positivity compared with the wide variety of types of negativity raises the possibility of some neural correlate to Tolstoy's view that "all happy families are alike; each unhappy family is unhappy in its own way" (Anna Karenina, p. 1, trans. Pevear and Volokhonsky 2000).

\section{Educational research on emotions}

As a result of the search methods described earlier, relatively few peer-reviewed studies of emotions and learning outcomes in education using physiological measures rather than or in addition to self-report emerged. Notable exceptions include Isen's body of collaborative work on positive affect and its relation to such learning components as creative problem solving and working memory, using a model based on the effects of dopamine. Happiness, mediated through the dopamine system, has been correlated with specific improved outcomes in cognitive flexibility, classification task ability, use of effective metacognitive strategies in interpersonal bargaining tasks, creativity experiments such as the classic "candle task," and working memory (Ashby et al. 1999; Yang et al. 2013; Carpenter et al. 2013). It is noteworthy that this body of research into positivity relies on an undifferentiated construct of positive emotion in the brain as the result of normative levels and 
metabolism of dopamine, thus conforming to the asymmetry of discrete positive and negative emotions typical of basic emotion theory.

Yeh et al.'s (2009) analysis of the role of catachol-O-methyltransferase (COMT) polymorphism, which causes the rate of dopamine metabolism to vary, in high-stakes test performance among Taiwanese adolescents constitutes an unusual example of a high- $N$ study with a population-representative sample in this field, and has inspired several other explorations of the cognitive effects of COMT polymorphism such as Colzato et al.'s (2010) application of COMT polymorphism to task-switching performance. However, while molecular and genetic explanations of cognitive variance such as the COMT literature have high predictive power and may be valuable in making public policy decisions which are equitable for diverse neurotypes (this is the accepted spelling in the neurodiversity advocacy community), they offer little data for assessing one learning system, or comparing one system versus another, because they do not measure temporal shifts in emotion during learning.

Azcarraga and Suarez (2013) report some preliminary findings on the use of EEG signals and pressure-sensitive mouse behaviors in college-age learning. This type of data is more promising on the temporal precision front, but at this time the authors' rates of correlation and $p$-values remain marginal. We would argue that this problem stems from their reliance on the academic emotions model, which may be too complex to permit accurate neuropsychological research. In game research using similar constructs, Mandryk et al. (2006) were unable to construct significant biological correlates for boredom and frustration (p. 1033); however, simpler concepts such as fun (a reasonable synonym for happiness construed as normative dopamine function) had wellcorrelated biological models with solid $p$-values (Mandryk et al. 2006.).

The conclusions of the emotions session of the 2012 Intelligent Tutoring Systems conference in Chania, Greece, likewise support a basic rather than complex construct of emotion as a more productive approach to studying and designing intelligent programs, though often developed with concepts taken from the GEW or something resembling the syntactic construal of simultaneous emotions. Grafsgaard, Boyer and Lester (2012, p. 56) achieve significant results using hidden Markov modeling to enable an intelligent tutoring system to accurately identify learner emotions; however, while they claim to work within an academic emotions framework, their construal of complex "academic" emotions rests on the simultaneous incidence of specific basic emotions on the face of the participant (see p. 54, Fig. 1 for "surprise," "doubt," and "confusion/frustration," all of which are represented as the result of at least two distinct signs).

Harley, Bouchet and Azevedo's (2012) work synthesizing valence states with cooccurring pairs of basic emotions (specifically using Ekman's set) found that most subjects were best described as experiencing multiple co-occurring basic emotions, although in 2012 they, in their review of literature, found only one other study that had ever considered a model using multiples of basic emotions (p. 44). The similarity of Harley et al.'s (2012) work, as well as the facial photographs if not their interpretation, to the syntactic approach bears further examination.

In conclusion, based on the pattern of educational studies conducted - and apparently not conducted-in recent years, one may reasonably conclude that the effect of the majority of basic emotions on learning remains poorly understood. Positive emotion and one sort of negative emotion-fear-have attracted scholarly attention, but very little research has been conducted on the interaction of other negative emotions with learning. Some research into anger and learning has begun to emerge very 
recently, though not necessarily in line with the presuppositions of contemporary cognitive neuroscience. Jaworska et al. (2012) found lowered levels of sustained attention in participants with high levels of trait anger, confirmed by EEG, though this study did not approximate a natural learning condition. Clément et al. (2013) found a markedly greater willingness, among both adults and children, to accept new (fictional) vocabulary presented by a happy compared to an angry avatar; though, as the comparison of an angry avatar to a neutral one was not significant, it is worth asking whether Clément et al.'s work is predominantly a study of anger, or a contribution to the study of happiness with anger being used as a novel alternate condition. Their work also raises the issue of disambiguating research on instructors' emotions from those of learners-despite the phenomenon of emotional contagion, these are not identical learning conditions.

Kim et al. (2014) found that anger was the strongest emotional predictor (in the negative) of achievement as measured by final grades in their multiple regression study of American secondary school students in an online mathematics course. However, a weakness of Kim et al.'s (2014) paper relative to this study is that the authors measured anger only using a self-report instrument, so the possibility that anger as it would be defined by biological neuroscience was not always present or to the degree reported, if survey participants were lacking in emotional self-knowledge. The survey also did not provide real-time data, as it was not embedded in the course shell but taken at a different time when students were thinking about the math course.

\section{Implications}

In summary, a consistent pattern emerges concerning emotion constructs in educational research: questions framed in terms of emotions that are recognized by basic emotion theory tend to yield sound results with low $p$-values, while questions framed in terms recognized only by academic emotion theory, even within the same study (since the academic emotions include the basic emotions) consistently show marked drops in $p$-value for those emotions, often to a point that most social science disciplines would consider non-significant. In addition, the negative basic emotions other than fear remain understudied.

While to some extent the lack of physiological measures in educational research can be attributed to lack of funding (the projects reviewed had partnerships ensuring more resources than is typical in education, such as Isen's frequent collaborations with management scientists), money does not appear to be the only factor restricting use of such methods. The challenges faced in modeling correlates to academic emotions in video game design studies (Mandryk et al. 2006) suggest that a problem with underlying theory is at work. The CHI 2006 conference at which Mandryk et al. presented their findings was sponsored by Google, Intel, Yahoo!, IBM, eBay, Cisco, and the NSF, among others, and in general the sector of video game studies, connected as it is with a highly profitable entertainment model, can be expected to attract large amounts of funding from corporate partners. Since there are similar results in recreational gaming studies that use concepts similar to those distinct to academic emotions, it may be inferred that money is not the only reason why educational research on emotions is out of step with other disciplines.

While objections have been raised that physiological instruments such as EEG are too invasive to constitute a realistic learning condition, the results of using EEG and similar instruments on gamers do not suggest that these devices interfere with the pleasure of 
gaming (Kivikangas et al. 2011); therefore, such methods show great promise for future research on human learning - but only if used in conjunction with a theory of emotion simple enough that the results are consistent and make sense. Within the simple and researchtested basic emotion paradigm, the greatest shortages of literature are on the effects of negative emotions other than fear, such as anger and disgust.

For these reasons, it may be hypothesized both that physiological studies of emotions in learning will generate more powerful results if a basic rather than academic emotions concept is used to guide study design, and that there is a need for studies of the effects of anger, disgust and other negative emotions other than fear, given the frequency of these emotions in everyday experience.

\section{Compliance with ethical standards}

Conflict of interest The authors declare that they have no conflict of interest.

OpenAccess This article is distributed under the terms of the Creative Commons Attribution 4.0 International License (http://creativecommons.org/licenses/by/4.0/), which permits unrestricted use, distribution, and reproduction in any medium, provided you give appropriate credit to the original author(s) and the source, provide a link to the Creative Commons license, and indicate if changes were made.

\section{References}

Ashby, F. G., Isen, A., \& Turken, U. (1999). A neuropsychological theory of positive affect and its influence on cognition. Psychological Review, 106(3), 529-550.

Azcarraga, J., \& Suarez, M. T. (2013). Recognizing student emotions using brainwaves and mouse behavior data. International Journal of Distance Education Technologies, 11(2), 1-15. https://doi.org/10.4018/ jdet.2013040101.

Bar-On, R. (2006). The Bar-On model of emotional and social intelligence (ESI). Psicothema, 18(supl.), 13-25. (Later than the 1997 first publication of Bar-On's survey instrument, but more informative.)

Ben-Ze'ev, A. (2000). The subtlety of emotions. Cambridge, MA: MIT Press.

Bostwick, J. A., Calvert, I. W., Francis, J., Hawkley, M., Henrie, C. R., Hyatt, F. R., et al. (2014). A process for the critical analysis of instructional theory. Education Technology Research and Development. https ://doi.org/10.1007/s11423-014-9346-5.

Carpenter, S. M., Peters, E., Västfäll, D., \& Isen, A. M. (2013). Positive feelings facilitate working memory and complex decision making among older adults. Cognition and Emotion. https://doi. org/10.1080/02699931.2012.698251.

Clément, F., Bernard, S., Grandjean, D., \& Sander, D. (2013). Emotional expression and vocabulary learning in adults and children. Cognition and Emotion. https://doi.org/10.1080/02699931.2012.724012.

Colzato, L. S., Waszak, F., Nieuwenhuis, S., Posthuma, D., \& Hommel, B. (2010). The flexible mind is associated with the catechol-O-methyltransferase (COMT) $\mathrm{Val}^{158}$ polymorphism: Evidence for a role of dopamine in the control of task-switching. Neuropsychologia. https://doi.org/10.1016/j.neuropsych ologia.2010.04.023.

Conference on Human Factors in Computing Systems (CHI 2006). Final program. Retrieved from http:// www.chi2006.org/docs/finalprogram2006.pdf.

Cooper, H. M. (1985). A taxonomy of literature reviews. Retrieved from http://files.eric.ed.gov/fulltext/ ED254541.pdf.

Csikszentmihalyi, M. (1990). Flow: The psychology of optimal experience. New York, NY: Harper \& Row.

D'Mello, S. (2013). A selective meta-analysis on the relative incidence of discrete affective states during learning with technology. Journal of Educational Psychology. https://doi.org/10.1037/a0032674.

Damasio, A. (1994). Descartes' error: Emotion, reason and the human brain. New York, NY: Penguin Books. 
Damm, L. (2011). Self-deception about emotion. The Southern Journal of Philosophy. https://doi.org/10.11 11/j.2041-6962.2011.00073.x.

Darwin, C. (1872). The expression of the emotions in man and animals. Retrieved from http://darwin-onlin e.org.uk/content/frameset?pageseq=1\&itemID=F1142\&viewtype=text. Octoer 13, 2015.

de Sousa, Ronald. (1987). The rationality of emotion. Cambridge, MA: MIT Press.

de Sousa, R. (2013). Emotion. In E. N. Zalta (Ed.), The stanford encyclopedia of philosophy (Spring 2014 ed.). Retrieved from http://plato.stanford.edu/archives/spr2014/entries/emotion/.

Dogan, I., Saß, C., Mirzazade, S., Kleiman, A., Werner, C. J., Pohl, A., et al. (2014). Neural correlates of impaired emotion processing in manifest Huntington's disease. SCAN. https://doi.org/10.1093/scan/ nst029.

Dyck, M., Loughead, J., Kellermann, T., Boers, F., Gur, R., \& Mathiak, K. (2011). Cognitive versus automatic mechanisms of mood induction differentially activate left and right amygdala. NeuroImage, 54, 2503-2513.

Ekman, P., Sorenson, R., \& Friesen, W. V. (1969). Pan-cultural elements in facial displays of emotion. Science. https://doi.org/10.1126/science.164.3875.86.

Eysenck, M. W. (1997). Anxiety and cognition. Hove, UK: Psychology Press.

Finkenauer, C., Engels, R. C. M. E., Meeus, W., \& Oosterwegel, A. (2002). Self and identity in early adolescence: the pains and gains of knowing who you are. In T. M. Brinthaupt \& R. M. Lipka (Eds.), Understanding early adolescent self and identity: Applications and interventions (pp. 25-55). Albany, NY: SUNY Press.

Goleman, D. (1995). Emotional intelligence. New York, NY: Bantam Books.

Goodkind, M. S., Sollberger, M., Gyurak, A., Rosen, H. J., Rankin, K., Miller, B., et al. (2012). Tracking emotional valence: The role of the orbitofrontal cortex. Human Brain Mapping. https://doi. org/10.1002/hbm.21251.

Grafsgaard, J. F., Boyer, K. E., \& Lester, J. C. (2012). Toward a machine learning framework for understanding affective tutorial interactions. In S. A. Cerri, W.J. Clancey, G. Papadourakis, \& K. Panourgia (Eds.), Intelligent tutoring systems (pp. 54-58). Proceedings of the 11th International Conference, ITS 2012, Chania, Greece, June 14-18.

Greenspan, S. I., \& Benderly, B. L. (1997). The growth of the mind: and the endangered origins of intelligence. Cambridge, MA: Da Capo Press.

Greenspan, S. I., \& Shank, S. (2009). The first idea: How symbols, language and intelligence evolved from our primate ancestors to modern humans. Cambridge, MA: Da Capo Press.

Harley, J. M., Bouchet, F., \& Azevedo, R. (2012). Measuring learners' co-occurring emotional responses during their interaction with an intelligent tutoring system in MetaTutor. In S. A. Cerri, W. J. Clancey, G. Papadourakis, K. Panourgia (Eds.), Intelligent tutoring systems (pp. 40-45). Proceedings of the 11th International Conference, ITS 2012, Chania, Greece, June 14-18.

Hong, J., Nie, Y., Heddy, B., Monobe, G., Ruan, J., You, S., et al. (2017). Revising and Validating Achievement Emotions Questionnaire - Teachers (AEQ-T). International Journal of Educational Psychology. https://doi.org/10.17583/ijep.2016.1395.

Jack, R. E. (2013). Culture and facial expressions of emotion. Visual Cognition. https://doi. org/10.1080/13506285.2013.835367.

Jankowski, K. F., \& Takahashi, H. (2014). Cognitive neuroscience of social emotions and implications for psychopathology: Examining embarrassment, guilt, envy, and schadenfreude. Psychiatry and Clinical Neurosciences. https://doi.org/10.1111/pcn.12182.

Jaworska, N., Berrigan, L., Fisher, D., Ahmed, A. G., Gray, J., Bradford, J., et al. (2012). A pilot student of electrocortical activity in dysfunctional anger: Decreased frontocortical activation, impaired attention control, and diminished behavioral inhibition. Aggressive Behavior, 38, 469-480.

Jepma, M., Verdonschot, R. S., van Steenbergen, H., Rombouts, S. A. R. B., \& Nieuwenhuis, S. (2012). Neural mechanisms underlying the induction and relief of perceptual curiosity. Frontiers in Behavioral Neuroscience, 6(5), 1-9.

Kandel, E. R. (2001). The molecular biology of memory storage: A dialogue between genes and synapses. Science. https://doi.org/10.1126/science.1067020.

Kant, I. (2000). Critique of the power of judgment (P. Guyer \& E. Matthews, Trans.). Cambridge, UK: Cambridge University Press (Original work published 1790).

Kelley, N. J., Hortensius, R., \& Harmon-Jones, E. (2013). When anger leads to rumination: Induction of relative right frontal cortical activity with direct current stimulation increases anger-related rumination. Psychological Science. https://doi.org/10.1177/095679761257384.

Killgore, W. D. S., \& Yurgelun-Todd, D. A. (2004). Activation of the amygdala and anterior cingulate during nonconscious processing of sad versus happy faces. NeuroImage, 21, 1215-1223. 
Kim, C., Park. S. W., \& Cozart, J. (2014). Affective and motivational factors of learning in online mathematics courses. British Journal of Educational Technology. https://doi.org/10.111 1/j.1467-8535.2012.01382.x.

Kivikangas, J. M., Chanel, G., Cowley, B., Ekman, I., Salminen, M., Järvelä, S., et al. (2011). A review of the use of psychophysiological methods in game research. Journal of Gaming and Virtual Worlds. https://doi.org/10.1386/jgvw.3.3.181_1.

LeDoux, J. (1998). The emotional brain: The mysterious underpinnings of emotional life. New York, NY: Simon and Schuster.

Leong, K., Chan, P., Grabovac, A., Wilkins-Ho, M., \& Perri, M. (2013). Changes in mindfulness following repetitive Transcranial Magnetic Stimulation for mood disorders. The Canadian Journal of Psychiatry, 58(12), 687-691.

Lichtenfeld, S., Pekrun, R., Stupnisky, R. H., Reiss, K., \& Murayama, K. (2012). Measuring students' emotions in the early years: The Achievement Emotions Questionnaire - Elementary School (AEQES). Learning and Individual Differences, 22, 190-201.

Mandryk, R. L., Atkins, S. A., \& Inkpen, K. M. (2006, April). A continuous and objective evaluation of emotional experience with interactive play environments. Paper presented at CHI 2006, Montréal, Canada. Retrieved from http://dl.acm.org/citation.cfm?id=1124926.

Mayer, J. D., Caruso, D. R., \& Salovey, P. (1999). Emotional intelligence meets traditional standards for an intelligence. Intelligence. https://doi.org/10.1016/s0160-2896(99)00016-1.

Mayer, J. D., \& Geher, G. (1996). Emotional intelligence and the identification of emotion. Intelligence. https://doi.org/10.1016/s0160-2896(96)90011-2.

Nussbaum, M. C. (2001). Upheavals of thought: The intelligence of emotions. Cambridge, UK: Cambridge University Press.

Panksepp, J. (1994). The basics of basic emotion. In P. Ekman \& R. J. Davidson (Eds.), The nature of emotion: Fundamental questions (pp. 20-24). Oxford, UK: Oxford University Press.

Pekrun, R., Goetz, T., Frenzel, A. C., Barchfeld, P., \& Perry, R. P. (2011). Measuring emotions in students' learning and performance: The Achievement Emotions Questionnaire (AEQ). Contemporary Educational Psychology, 36(1), 36-48.

Pekrun, R. \& Stephens, E. J. (2012). Academic emotions. In K. Harris., S. Graham, T. Urdan, S. Graham, J. M. Zeidner, \& M. Zeidner (Eds.), APA Educational Psychology Handbook, Vol. 2 (pp. 3-31). Washington, D.C.: American Psychological Association.

Phan, K. L., Wager, T., Taylor, S. T., \& Liberzon, I. (2001). Functional neuroanatomy of emotion: A metaanalysis of emotion activation studies in PET and fMRI. NeuroImage, 16(2), 17-18. https://doi. org/10.1006/nimg.2002.1087.

Pishghadam, R., Zabetipour, M., \& Aminzadeh, A. (2016). Examining emotions in English language learning classes: A case of EFL emotions. Issues in Educational Research, 26(3), 508-526.

Plutchik, R. (2000). A psychoevolutionary theory of emotion. Ch. 4 in Emotions in the practice of psychotherapy, Washington, D.C.: American Psychological Association. Retrieved from http://psycnet.apa. org/psycinfo/2000-05991-000.

Rorty, Amélie (Ed.). (1980). Explaining emotions (pp. 103-126). Los Angeles: University of California Press.

Ross, W. D. (Ed.). (1959). Aristotle, Rhetoric 1378a20. Oxford, UK: Clarendon Press. Retrieved from open-source archive at http://www.perseus.tufts.edu/hopper/text?doc=Perseus\%3Atext\%3A199 9.01.0059\%3Abekker\%20page\%3D1378a.

Sambataro, F., Dimalta, S., Di Giorgio, A., Taurisano, P., Blasi, G., Scarabino, T., et al. (2006). Preferential responses in amygdala and insula during presentation of facial contempt and disgust. European Journal of Neuroscience. https://doi.org/10.1111/j.1460-9568.2006.05120.x.

Scherer, K. R. (1994). Toward a concept of "modal emotions". In P. Ekman \& R. J. Davidson (Eds.), The nature of emotion: Fundamental questions (pp. 25-31). Oxford, UK: Oxford University Press.

Scherer, K. R. (2005). What are emotions? And how can they be measured? Social Science Information, 44(4), 693-727.

Seipp, B. (1991). Anxiety and academic performance: A meta-analysis of findings. Anxiety Research, 4, $27-41$.

Selye, H. (1976). Forty years of stress research: Principal remaining problems and misconceptions. CMA Journal, 115, 53-55.

Sharpe, B. (n.d.). Digging into dissonance: Distress, eustress, and the student experience. Retrieved from http://www.freireproject.org/wp-content/uploads/2014/04/Digging-Into-Dissonance-Journal-Article-. pdf, October 13, 2015. 
Starkey-Perret, R., Deledalle, A., Jeoffrion, C., \& Rowe, C. (2017). Measuring the impact of teaching approaches on achievement-related emotions: The use of the Achievement Emotions Questionnaire. British Journal of Educational Psychology. https://doi.org/10.1111/bjep.12193.

Steiner, E. (1988). Methodology of theory building. Sydney, Australia: Educoogy Research Associates.

Tolstoy, L. (2000). Anna Karenina (R. Pevear \& L. Volokhonsky, Trans.). New York, NY: Penguin Books.

Ulrich, M., Keller, J., Hoenig, K., Waller, C., \& Grön, G. (2014). Neural correlates of experimentally induced flow experiences. NeuroImage, 86, 194-202.

Weissman, D. H., Roberts, K. C., Visscher, K. M., \& Woldorff, M. G. (2006). The neural bases of momentary lapses in attention. Nature Neuroscience, 9, 971-978.

Yang, H., Yang, S., \& Isen, A. (2013). Positive affect improves working memory: Implications for controlled cognitive processing. Cognition and Emotion, 27(3), 474-482.

Yeh, T., Chang, C., Hu, C., Yeh, T., \& Lin, M. (2009). Association of catechol-O-methyltransferase (COMT) polymorphism and academic achievement in a Chinese cohort. Brain and Cognition, 71, 300-305.

Yu, R., Mobbs, D., Seymour, B., Rowe, J. B., \& Calder, A. J. (2014). The neural signature of escalating frustration in humans. Cortex, 54, 165-178.

Zeidner, M. (1998). Test anxiety: The state of the art. New York, NY: Plenum Press.

Publisher's Note Springer Nature remains neutral with regard to jurisdictional claims in published maps and institutional affiliations.

Joy A.R. Eliot is a Ph.D. candidate at the University of Central Florida. Ms. Eliot's work focuses on the role of negative emotion cycles, particularly anger and disgust, in learners' relationship to e-learning and gamebased learning.

Atsusi Hirumi Ph.D., is a Professor of Instructional Design and Technology with a joint appointment with the Department of Medical Education at the University of Central Florida. Dr. Hirumi's research focuses on advancing experiential learning and simulation-based training by integrating elements of story, game and play with experiential learning principles. 